DOI: https://doi.org/10.12957/redoc.2018.32529

Revista Docência e Cibercultura

\title{
DA TELEVISÃO ANALÓGICA AOS CANAIS DO YOUTUBE NA INTERNET: OUTRAS FORMAS DE PRODUZIR E COMPARTILHAR ${ }^{1}$
}
FROM ANALOGUE TELEVISION TO YOUTUBE CHANNELS ON THE INTERNET: OTHER WAYS TO PRODUCE AND SHARE

\section{DE LA TELEVISIÓN ANALÓGICA A LOS CANALES DE YOUTUBE EN INTERNET: OTRAS FORMAS DE PRODUCIR Y COMPARTIR}

Simone Lucena ${ }^{2}$

Resumo: O objetivo deste artigo é apresentar alguns aspectos da história da televisão analógica no Brasil bem como entender as potencialidades da TV digital, da WebTV e da rede YouTube. A relevância desde texto, que é uma pesquisa bibliográfica, está no fato de discutir novos formatos para a produção audiovisual na internet e sua importância para a educação. Para tanto utilizamos referenciais como Lucena (2009, 2012), Lemos (2003, 2009), Lévy (2000), Santaella (2007) e Santos (2000). A televisão analógica foi uma invenção desenvolvida em meados do século XX, porém ao longo de algumas décadas a forma como inicialmente a televisão foi pensada tem se modificado. A grande transformação no sistema televisivo surgiu no inicio do século XXI com a TV digital. A TV digital é na verdade uma nova mídia. Não se trata de um aperfeiçoamento tecnológico, mas de uma mídia, que combina e absorve as tecnologias existentes e que poderá produzir outras tantas mídias, a depender das escolhas políticas. É também no início do século XXI que temos uma expansão da internet por meio de fibras e óptica, das redes Wi-fi e das tecnologias móveis que ampliam as potencialidades da cibercultura ao disponibilizar novas interfaces de comunicação, produção e publicação de conteúdos. Para a educação estas potencialidades da cibercultura são de grande importância, pois possibilita novas formas de produzir e compartilhar saberes e culturas. Palavras-chave: Televisão analógica, TV digital, WebTV, Cibercultura, Educação

Submetido em: 29/01/2018 - Aceito em: 20/02/2018 - Publicado em: 25/06/2018.

${ }^{1}$ Este artigo foi produzido no âmbito da pesquisa de Pós-doutorado financiada pelo Edital CAPES/FAPITEC/SE N 01/2016 - Programa de Apoio a Pós-Doutorado no Estado de Sergipe (PPDOCSE).

${ }^{2}$ Pós-doutoranda em Educação (Proped/UERJ). Doutora em Educação pela UFBA. Mestre em UFSC. Graduada em Pedagogia pela UNEB. Professora do Departamento de Educação da Universidade Federal de Sergipe (UFS) Campus Prof. Alberto Carvalho. Professora permanente do Programa de Pós-graduação em Educação da UFS. Líder do Grupo de Pesquisa Educação e Culturas Digitais (ECult/UFS/CNPq) http://grupoecult.blogspot.com.br. E-mail: sissilucena@gmail.com Orcid: http://orcid.org/0000-0003-1636-7707 


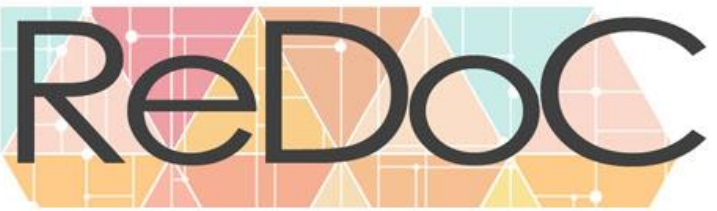

Revista Docência e Cibercultura

Abstract: The purpose of this article is to present some aspects of the history of analogue television in Brazil as well as to understand the potential of digital TV, WebTV and the YouTube network. The relevance from the text, which is a bibliographical research, lies in the fact of discussing new formats for audiovisual production on the internet and its importance for education. In order to do this, we use references such as Lucena (2009, 2012), Lemos (2003, 2009), Lévy (2000), Santaella (2007) and Santos (2000). Analog television was an invention developed in the midtwentieth century, but over the course of a few decades the way television was first thought has changed. The great transformation in the television system emerged at the beginning of the 21 st century with digital TV. Digital TV is actually a new medium. It is not a technological improvement, but a media, which combines and absorbs the existing technologies and that can produce so many media, depending on the political choices. It is also at the beginning of the 21 st century that we have an expansion of the internet through fiber and optics, Wi-Fi networks and mobile technologies that increase the potential of cyberculture by providing new interfaces for communication, production and publication of content. For education these potentialities of cyberculture are of great importance, as it enables new ways of producing and sharing knowledge and cultures.

Keywords: Analog TV, Digital TV, WebTV, Cyberculture, Education

Resumén: El objetivo de este artículo es presentar algunos aspectos de la historia de la televisión analógica en Brasil y también entender la posibilidades de la TV digital, de la WebTV y de la red social YouTube. La relevancia de este texto, que es una investigación bibliográfica, está en el hecho de discutir nuevos formatos para la producción audiovisual en internet y su importancia para la educación. Para esto utilizamos referencias como Lucena (2009, 2012), Lemos (2003, 2009), Lévy (2000), Santaella (2007) y Santos (2000). La televisión analógica fue un invento de mitad del siglo XX, y a lo largo de algunas décadas la forma como inicialmente fue pensada se ha modificado. La TV digital es en realidad un nuevo medio. No se trata de un perfeccionamiento tecnológico, y sí de un medio, que combina y absorbe las tecnologías existentes y que podrá producir nuevos medios dependiendo de opciones políticas. También fue en el inicio del siglo XXI que tenemos una expansión de internet por medio de fibras ópticas, de redes Wi-Fi y de las tecnologías móviles que amplían las posibilidades de la cibercultura al ofrecer nuevas interfaces de comunicación, producción y publicación de contenidos. Para la educación estas posibilidades que ofrece la cibercultura son de gran importancia, pues traen nuevas formas de producir y compartir saberes y culturas.

Palabras clave: TV analógica, televisión digital, WebTV, cibercultura, educación 


\section{A CHEGADA DA TELEVISÃO NO BRASIL}

No Brasil o aparelho de televisão está presente em cerca de $98 \%$ dos lares. De acordo com dados da pesquisa "TIC em Domicílios" realizada pelo Comitê Gestor da Internet no Brasil (CGI, 2016), 50\% das residências no Brasil possuem o computador. Deste percentual há uma maior inserção de computadores portáteis, pois $64 \%$ dos domicílios possuem laptop ou notebook. Estes dados nos mostram que na maioria dos lares brasileiros o acesso a informação ainda é por meio da televisão principalmente em regiões distantes dos grandes centros urbanos onde não há conexão a rede internet.

Ao longo de algumas décadas a forma como inicialmente a televisão foi pensada tem se modificado. Nos primeiros anos da tevê $\hat{e}^{3}$ sua programação era ao vivo e transmitidas diretamente de locais como auditórios e teatros. A possibilidade de gravar os conteúdos, editá-los e transmiti-los posteriormente surge apenas na década de 1950 quando foi criado o videotape.

A primeira televisão com imagens em preto e branco a entrar em funcionamento no mundo foi em Paris, em 1935, na Torre Eiffel (RABAÇA \& BARBOSA, 2001). No ano seguinte, a emissora British Broadcasting Corporation (BBC) de Londres iniciou suas primeiras transmissões. Nos Estados Unidos a primeira transmissão regular é iniciada em 1941, quando a Columbia Broadcasting System (CBS) apresentou o primeiro noticiário sobre o envolvimento dos EUA na Segunda Guerra Mundial. No Japão a Nippon Hôsô Kyôkai (NHK) foi fundada em 1926, porém apenas com transmissão de rádio, já que as transmissões televisivas somente foram iniciadas em 1953.

A popularização da televisão no mundo ocorreu após a Grande Guerra, em 1945, quando foi possível o início da produção em larga escala dos aparelhos televisivos nos países industrializados. No Brasil, a primeira emissora foi instalada em 1950, no entanto, anteriormente, em 1939, foi realizada, numa Feira de Amostra no Rio de

\footnotetext{
${ }^{3}$ Neste texto optamos por utilizar a grafia "tevê" para nos referir à televisão analógica e a grafia "TV" para nos referir à televisão digital e as outras formas televisivas presentes na internet. Esta escolha se deve ao fato do sistema de TV digital e WebTV serem uma nova mídia que inserem e remixam diferentes linguagens e formatos mão podendo esta razão ser tratada como uma evolução da televisão analógica.
}

\begin{tabular}{l|l|l|l|l|l|l|}
\hline C Redoc & Rio de Janeiro & v.2 & n.2 & p. 33 & Maio/Agosto. 2018 & ISSN 2594-9004
\end{tabular}




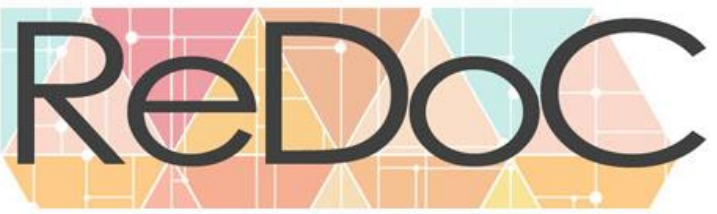

Revista Docência e Cibercultura

Janeiro, a primeira transmissão através de aparelho de tevê. Com o início da Segunda Guerra Mundial, as transmissões das televisões do mundo inteiro foram suspensas, sendo retomadas após o final da guerra. A TV Tupi de São Paulo, a primeira emissora do Brasil, foi fundada pelojornalista e empresário Assis Chateaubriand em 1950. Foi nesse mesmo período que a televisão surgiu em outros países da América Latinacomo México e Cuba.

O desenvolvimento da televisão brasileira pode ser divido em duas fases, conforme indicado por Caparelli (1986). A primeira fase compreende o período de 1950 a 1964, onde havia uma maior concentração de produção de programas nas cidades do Rio de Janeiro e de São Paulo. É também neste período que há uma grande importação de programas estrangeiros. Vale ressaltar que a televisão surge como um eletrodoméstico de elite, pois devido ao alto preço dos aparelhos, poucas pessoas tinham condições de adquiri-los.

A programação da televisão neste período consistia em reproduzir os programas transmitidos pelo rádio. As novelas eram adaptações de peças teatrais e quase não havia publicidade na tevê, que, por ser um veículo de comunicação novo, não tinham a confiança das agências publicitárias, que preferiam investir em anúncios nos meios de maior circulação como jornais, revistas e rádio. Como a maior produção dos programas televisivos estava na região sudeste, as emissoras locais e regionais que começaram a surgir tanto no nordeste como no sul do país vão se tornando difusoras ou afiliadas das grandes empresas nacionais.

A segunda fase da televisão no Brasil é iniciada após 1964 e vai até os dias atuais. Esta fase é marcada pela decadência da TV Tupi e de outras pequenas emissoras e pela ascensão da TV Globo que, após assinatura de contrato com o grupo americanoTime-Life, entrou num "acentuado modoracional e capitalista de produção, comtécnicas administrativas das mais modernas" (Caparelli, 1986, p. 12).

Embora a primeira televisão brasileira tenha sido uma emissora comercial, isto é, uma empresa privada voltada para a publicidade e para a comercialização de produtos por meio de anúncios, já existia um grupo de educadores da Rádio Roquete Pinto que havia solicitado do governo federal a concessão de um canal de tevê educativa. Esses 


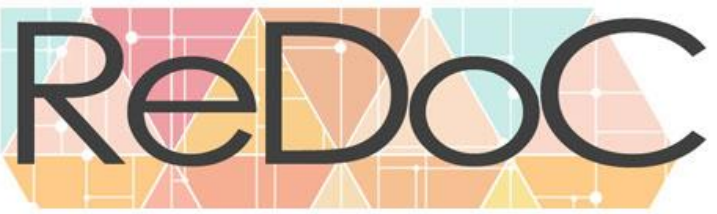

Revista Docência e Cibercultura

educadores pretendiam dar continuidade ao trabalho de educação à distância que já desenvolviam na rádio. Apesar da concessão do governo ter sido aprovada em 1952, por problemas de ordem político-administrativo, a primeira televisão educativa no Brasil somente foi criadaem 1967: a TVE/RJ.

Na década de 1980 iniciava-se no Brasil os serviços de TV por assinatura sendo a TVA - Serviços Especiais de TV por Assinatura - o primeiro serviço nãoconvencional (sinal aberto) de TV explorado no país, regulamentado peloDecreto 95.744 de 23 de fevereiro de 1888 "como sendo um serviço de telecomunicações destinado à distribuiçãode sons e imagens para subscritores, através de sinais codificados" (JAMBEIRO, 2002, p. 205). Em 1995 foi instituída a Lei nº 8.977 que dispõe sobre os serviços de TV a Cabo. O artigo 23 desta lei estabelece que a operadora de TV a Cabo, na sua área de prestação do serviço, deverá tornar disponíveis canais, alguns gratuitos, destinados para uso legislativo, comunitário e universitário. O canal universitário deverá ser compartilhado entre as universidades localizadas no município ou em cidades da área de prestação do serviço.

As TVs Educativas foram criadas por meio do Decreto-Lei 5.198, de 03 de janeiro de 1967. Este decreto instituiu a Fundação Centro Brasileiro de TV Educativa com a finalidade de produzir, comprar e distribuir programas para transmissões educativas. Na época, era o Ministério da Educação que controlava o conselho diretor que elegeu, em 03 de abril de 1967, como primeiro presidente da TV Educativa.

Dois aspectos são considerados relevantes para a implantação das TVs Educativas no Brasil. Um desses aspectos foi a pressão internacional realizada pela UNESCO para que os países em desenvolvimento utilizassem a televisão comoummeio de atender às necessidades educacionais. $\mathrm{O}$ outro aspecto está relacionado com $\mathrm{O}$ processo de industrialização pelo qual o país estava passando naquele momento e que requeria mão-de-obra qualificada e, desta forma, a TV era um dos meios de se obter esta qualificação viacursos de teleducação.

Para coordenar os programas da teleducação foi criado o Programa Nacional de Teleducação (PRONTEL) - Decreto 70.185 de 23 de fevereiro de 1972 - com o objetivo de coordenar, promover e integrar o uso e o desenvolvimento de técnicas 


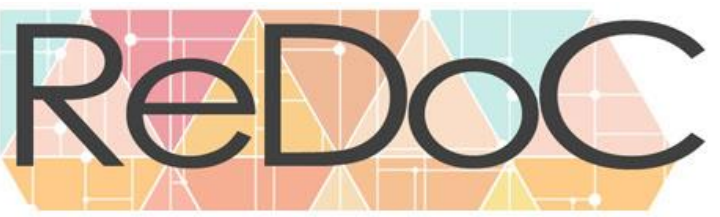

Revista Docência e Cibercultura

educacionais para a elaboração de programas de rádio e TV que pudessem ser transmitidos na rede de radiodifusão nacional educativa. Para que tais programas fossem desenvolvidos, as TVs educativas contavam com exclusivo financiamento de verbas públicas, porque de acordocom o Código Brasileiro de Telecomunicações estas emissoras não poderiam aceitar publicidade direta ou indireta nem nenhum outro patrocínio que não fosse oriundo dos governos municipal, estadual ou federal, universidades e fundações públicas.

A partir da década de 1990 asituação das TVs educativas mudou umpouco no que se refere ao seu financiamento. Algumas destas TVs, que tiveram seusorçamentos reduzidos, optaram porbuscarpatrocinadoresparaseusprogramas, como foi o caso da TV Cultura de São Paulo. Da mesmaforma, outras emissoras educativas de rádio e TV, quetambém passavam pelamesmaescassez de recursosque a TV Cultura de São Paulo, optaram porbuscarapoio cultural para seus programas como forma de garantir a sua manutenção.

Há mais de 20 anos, as TVs educativas sobrevivem com limitadas verbas governamentais e com uma legislação que impossibilita o seu desenvolvimento. Isso ocorre porque, segundo Mota (1992), no Brasil a TV educativa foi criada comum caráter estatal e não de TV pública, o que é completamente diferente. A televisão estatal se caracteriza porser:

Rede oficial onde o custeio é realizado através da alocação de verbas públicas federais e estaduais, com a função de complementar a educação, e informarações do poder público que são de interesse da população em geral. O critério de nomeação dos seu sdirigentes é político (MOTA, 1992, p. 83).

A falta de recursos da maioria das TVs educativas do país tem contribuido para o fato de que essas emissoras tenham poucas possibilidades de produção de programas que retratem a identidade cultural da sua região ou crie novos conteúdos televisivos próprios. Por esta razão, acabam retransmitindo os programas produzidos pela TVE do Rio de Janeiro e pela TV Cultura de São Paulo, na maior parte do tempo da sua programação. Isso reforça a premissa de que se as TVs educativas tivessem melhores recursos, aliados a uma gestão pública qualificada, poderiam ser produtoras de 


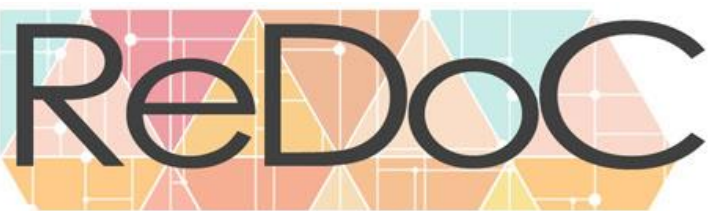

Revista Docência e Cibercultura

programas locais, regionais que abordassem sua cultura e sua arte.

Nesse sentido, para a democratização da comunicação precisamos pensar na construção TVs educativas que subvertam a lógica do mercado, que sempre dissemina os conteúdos partindo sempre do centro (emissoras geradoras) para as periferias (emissoras retransmissoras). A comunicação é direito do cidadão e o pluralismo é uma obrigação social e não apenas uma dádiva das mídias (REY, 2002).

Uma boa alternativa de rede pública de televisão será aquela capaz de colocar em circulação as produções das periferias num movimento que Martín-Barbero (2002) coloca como "indo tanto do centro para a periferia como das periferias entre si e para o centro" (p. 75). Para que isso ocorra é certo que o investimento tecnológico é imprescindível, mas este apenas não é suficiente. É necessário que haja políticas de comunicação capazes de veicular as produções locais, regionais e comunitárias para todo o país de forma bidirecional.

Isso será possível principalmente com a inserção das tecnologias de informação e comunicação (TIC) na disseminação dos conteúdos audiovisuais, pois as TIC possibilitam a construção de redes de conhecimentos, potencializam o fortalecimento da cidadania, da autonomia e da cultura e disponibilizam a produção de conteúdos.

No Brasil além das TVs Educativa temos também as TVs Universitárias (TVU) que são canais de televisão mantidos por universidades. A Associação Brasileira de Televisão Universitária (ABTU) foi fundada em 2000 para congregar as Instituições de Ensino Superior (IES) que produzem televisão educativa e cultural. Hoje estas TVU trocam produções audiovisuais por meio da Rede de Intercâmbio de Televisão Universitária (RITU) criado pelo Laboratório de Vídeo Digital da Universidade Federal da Paraíba (LAVID/UFPB). Trata-se de uma rede de compartilhamento dos vídeos produzidos pelas televisões universitárias, com troca de conteúdo para a construção de uma grade de programação nacional, a ser usada por qualquer canal universitário na íntegra ou com adaptações locais na programação. O compartilhamento dos vídeos é feito por meio de uma interface Web que foi desenvolvida numa parceria do LAVID com um Grupo de Trabalho da Rede Nacional de Pesquisa (RNP), financiadora do 


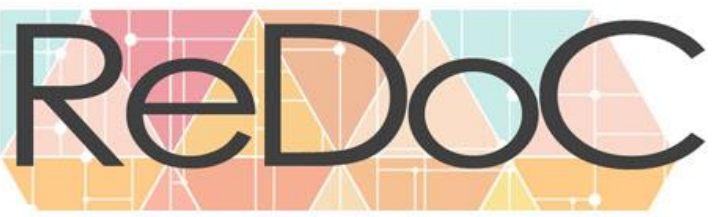

Revista Docência e Cibercultura

projeto $^{4}$.

Inspirada na proposta da RITU, a Faculdade de Educação da UFBA desenvolveu "Rede de Intercâmbio de Produção Educativa" (RIPE), em parceria com LAVID/UFPB, com o objetivo de desenvolver um sistema e uma dinâmica de produção e veiculação de produtos audiovisuais disponíveis para os processos de ensino e aprendizagem das escolas públicas do ensino básico do Estado da Bahia, com intensivo uso de software livre, de forma descentralizada e com base em princípios colaborativos. ${ }^{5}$

\section{TV DIGITAL E SUAS POSSIBILIDADES}

As discussões, estudos e pesquisas sobre TV digital no Brasil iniciaram em 2003. Apesar da TV digital ser uma nova mídia sua maior propaganda é que trata-se de uma televisão com melhor qualidade de imagem e som. Isso é verdade, mas é também apenas uma parte das transformações que esta nova mídia pode trazer para a sociedade.

Para Mota (2005), a TV digital não é apenas um aperfeiçoamento tecnológico, mas uma nova mídia, que combina e absorve as tecnologias existentes e que poderá produzir outras tantas mídias, a depender das escolhas políticas. A TV digital é, na verdade, uma convergência de mídias - o computador e a televisão. Isso possibilita que novas aplicações, em que os sujeitos são colocados como atores do processo sejam possíveis de serem realizadas, o que antes era impensável na TV analógica. São aplicações como comércio eletrônico, e-mails e jogos eletrônicos que utilizam atributos da hipermídia e da interatividade comuns nos computadores.

Para acessar a todos os serviços e programações da TV digital é necessário a existência de um terminal de acesso para a televisão. Este terminal pode ser uma Unidade Recptora-Decodificadora (URD) também conhecida pelo nome de set-top-box. Trata-se de um equipamento capaz de abordar os sinais captados por uma antena (VHF/UHF) e convertê-los em sinal analógico passível de tratamento e reprodução, por meio do aparelho convencional de televisão.

\footnotetext{
${ }^{4}$ Mais informações sobre a RITU estão disponíveis no site da ABTU <https://www.abtu.org.br/>

${ }^{5}$ Os conteúdos da RIPE podem ser acessado em <http://ripe.ufba.br/>
}

\begin{tabular}{l|l|l|l|l|l|l|} 
(C) Redoc & Rio de Janeiro & v.2 & n.2 & p. 38 & Maio/Agosto. 2018 & ISSN 2594-9004
\end{tabular}




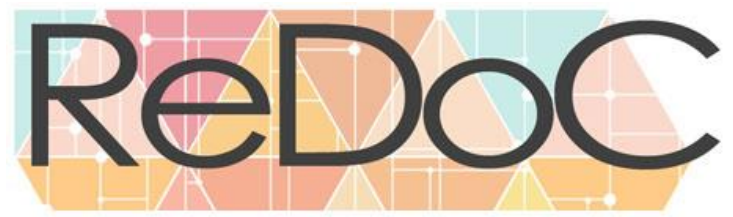

Revista Docência e Cibercultura

\section{Figura1 - Transmissão de sinal para TV Digital}

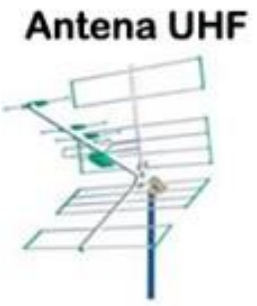

RF IN

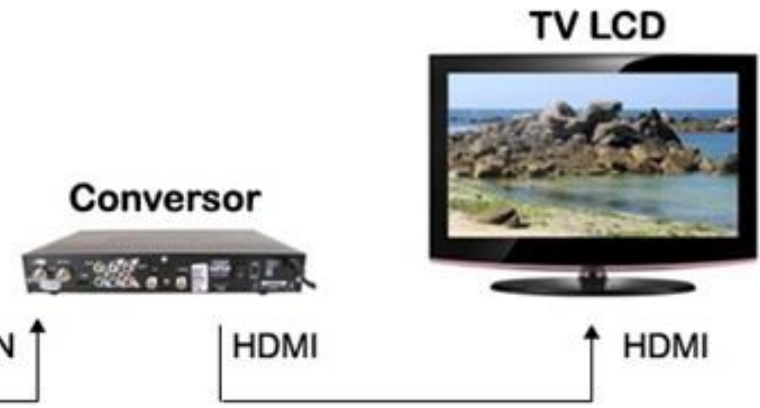

TV LCD

Fonte: TV Digital Brasileira. Disponível em: http://www.dtv.org.br/index.php/tv-digital/o-que-e-tvdigitalacessado em 22/07/2017

Estudos apresentados pela Fundação Centro de Pesquisa e Desenvolvimento em Telecomunicações (CPqD), no Relatório Integrador dos Aspectos Técnicos e Mercadológicos da Televisão Digital e no Modelo de Referência para o Sistema Brasileiro de TV Digital apontam diferentes formas de implementação da interatividade na TV digital. No Brasil desde o final do século XX que já haviam sido iniciados estudos sobre a TV digital, porém foi somente a partir de 2003 que estas pesquisas se intensificaram principalmente por incentivos do governo brasileiro.

Os padrões de TV digital mais utilizados no mundo foram criados no final do século XX por países líderes em desenvolvimento tecnológico foram: O Japão desenvolveu o padrão ISDB - Integrated Services Digital Broadcasting; A União Europeia criou o chamado padrão europeu DVB - Digital Vídeo Broadcasting e os Estados Unidos produziram o ATSC - Advanced Television Systems Committee. A China iniciou em 2003 os primeiros testes para o desenvolvimento do seu sistema próprio de TV digital o Digital Terrestrial Multimedia Broadcast (DTMB). O mapa a seguir mostra como estes padrões estão espalhados pelos países no mundo disputando o mercado da TV digital.

Figura 2-Sistemas de TV digital no mundo

\begin{tabular}{|l|l|l|l|l|l|l|}
\hline C Redoc & Rio de Janeiro & v.2 & n.2 & p. 39 & Maio/Agosto. 2018 & ISSN 2594-9004 \\
\hline
\end{tabular}




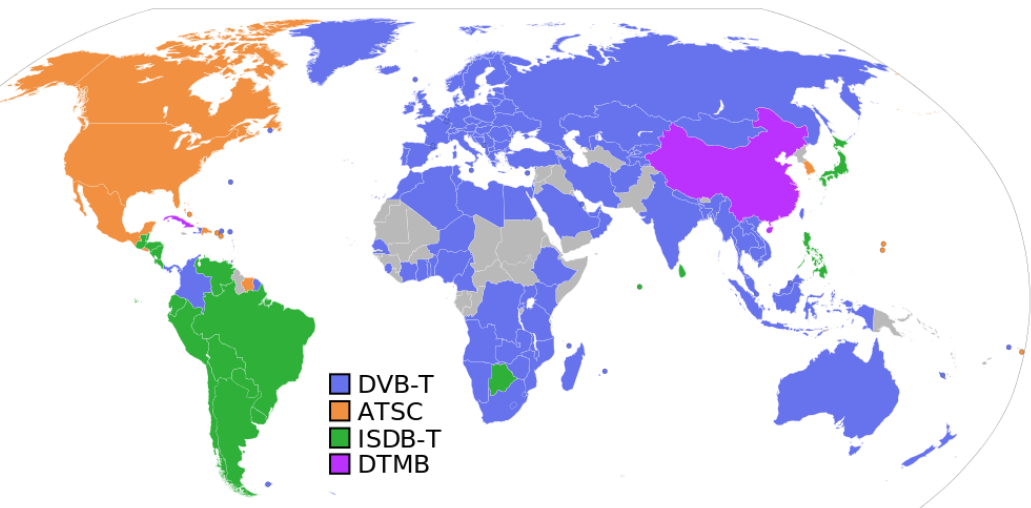

Fonte: Wikipedia.Disponível

em:https://en.wikipedia.org/wiki/List_of_digital_television_deployments_by_country\#Braz il acessado em 22/07/2017.

Cada um dos sistemas ISDB, ATSC e DVB foram desenvolvidos de acordo com as características econômicas, políticas e culturais de cada país que o concebeu. Para a implantação de um destes padrões nos demais países faz-se necessária algumas adaptações para a realidade local. Isso torna imprescindível a reflexão sobre o que cada país deseja ou espera alcançar com a TV digital, uma vez que esta mídia não é um mero desenvolvimento da televisão analógica, mas um novo e potente meio capaz de proporcionar grandes transformações econômicas, políticas, educacionais e sociotécnicas.

\section{O SISTEMA BRASILEIRO DE TELEVISÃO DIGITAL - SBTVD}

Os estudos sobre a implantação da TV digital (TVD) no Brasil não é recente. Há mais de quinze anos a TVD é estudada por pesquisadores brasileiros. Em 1991 o Ministério das Comunicações (MiniCom) criou a Comissão Assessora de Televisão (COM-TV) que mais tarde iniciou,juntamente com a Associação Brasileira de Emissoras de Rádio e TV (ABERT) e a Sociedade de Engenharia de Televisão e Telecomunicações (SET), os primeiros estudos sobre televisão digital com o objetivo de 


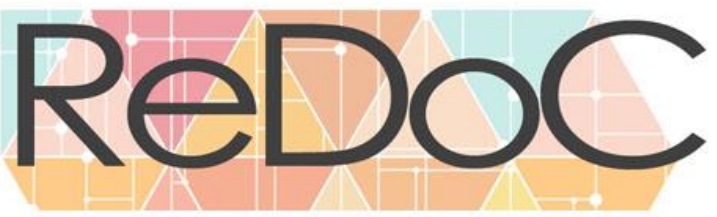

Revista Docência e Cibercultura

preparar os radiodifusores para a migração para o sistema digital (BOLAÑO \& BRITTOS, 2007).

A partir de 1995, durante o governo do presidente Fernando Henrique Cardoso, foram ampliados os estudos sobre a análise dos três sistemas de TVD em funcionamento no mundo- ATSC, DVB e ISDB. Esses estudos foram realizados pela ABERT, SET e pelo Centro de Pesquisa e Desenvolvimento em Telecomunicações $(\mathrm{CPqD})$, que nesta época desenvolvia estes estudos como membro da SET, pois havia no $\mathrm{CPqD}$, desde a década de 1980, um grupo de pesquisa sobre vídeo digital.

Em janeiro de 2003, quando Luiz Inácio Lula da Silva assumiu a presidência do Brasil, ainda não havia uma decisão sobre qual o modelo de TV digital seria adotado no país. Havia uma pressão dos empresários da comunicação para que o modelo japonês fosse escolhido, pois nos testes realizados, na opinião dos radiodifusores, era o que mais atendia às suas necessidades, no que se referia à imagem e som de alta qualidade (LUCENA, 2012). Não obstante, era preciso levar o debate para a sociedade, pois a implantação da TV digital não é apenas uma simples troca de tecnologia analógica para digital. A televisão digital traz em seu bojo novas possibilidades e aplicabilidades; uma delas é a forma de assistir um programa, por exemplo, alterada para outro formato mais interativo e dinâmico.

No início do governo Lula, a ênfase do discurso sobre a TV digital já não era mais a adoção completa de um sistema internacional e sim o desenvolvimento de um Sistema Brasileiro de Televisão Digital (SBTVD) que pudesse atender às necessidades

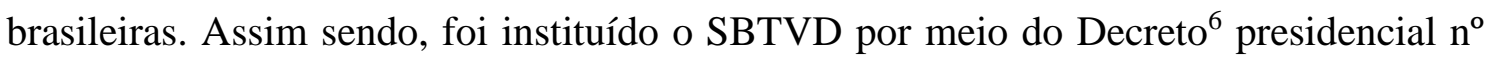
4.901 de 26 de novembro de 2003.

Para o desenvolvimento do SBTVD foi formada uma verdadeira rede de produção científica, composta por 1.200 pesquisadores e 23 instituições envolvendo profissionais de diversas áreas do país, como objetivo de produzir uma solução tecnológica que atendesse às necessidades da sociedade brasileira. Essa rede foi formada pelos consórcios criados por universidades e centros de pesquisa brasileiros

${ }^{6}$ Disponívelemhttp://www.planalto.gov.br/ccivil 03/decreto/2003/D4901.htm 


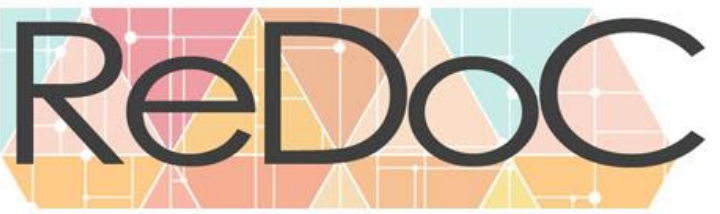

Revista Docência e Cibercultura

que acataram a chamada-pública MC/MCT/FINEP/FUNTTEL - 01/2004 apresentando propostas de projetos nas áreas e temas definidos como prioritários para o desenvolvimento do Sistema Brasileiro de Televisão Digital. Entretanto apesar de todos estes esforços em 2006 o Brasil adotou a norma chamada nipo-brasileira também conhecida como ISDB-T por meio do Decreto 5.820 de 29 de junho de 2006 que instituiu:

I - SBTVD-T - Sistema Brasileiro de Televisão Digital Terrestre - o conjunto de padrões tecnológicos a serem adotados para transmissão e recepção de sinais digitais terrestres de radiodifusão de sons e imagens.

II - ISDB-T - Integrated Services Digital Broadcasting Terrestrial serviço de radiodifusão digital terrestre, integrado por padrões tecnológicos internacionais definidos na União Internacional de Telecomunicações - UIT.

É importante ressaltar que o governo brasileiro, ao oficializar suã opção pelo padrão japonês, em detrimento do desenvolvimento de um sistema nacional e inovador, desperdiçou a oportunidade de tornar o país um produtor de tecnologia avançada e não apenas um utilizador de recursos tecnológicos produzidos externamente e que nem sempre atendem às necessidades brasileiras, além de inviabilizar o processo de democratizar a comunicação.

\section{A WEB TV E AS MUDANÇAS DE ESPECTADOR PARA A(U)TOR}

A criação e o desenvolvimento da internet em meados do século XX produziu uma verdadeira transformação na sociedade alterando as formas das pessoas pensarem, agirem, se relacionarem, consumirem e produzirem conhecimentos. Talvez os americanos não tivessem imaginado a dimensão que esta rede ganharia quando a Advance Research Projets Agency (ARPA), por meio do departamento Information Processing Techniques Office (IPTO), criou na década de 1960 a ARPANET, um pequeno programa de computador para interligar os computadores dos grupos de pesquisa que trabalhavam para a Agência e onde estavam armazenados importantes dados do governo. Com a utilização da ARPANET os americanos não corriam mais o 


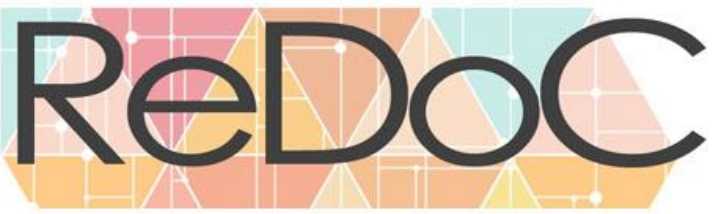

Revista Docência e Cibercultura

risco de perder suas informações, caso o país fosse bombardeado durante uma guerra.

Contudo, a ARPANET não ficou restrita apenas ao uso militar, pois aos poucos novos pesquisadores e universidades passaram a integrar a rede trocando informações e criando outras possibilidades de comunicação. A utilização da rede pelos centros de pesquisa fez com que outras redes fossem criadas, a ponto de, em 1983, a ARPANET se tornar ARPA-INTERNET e, finalmente, INTERNET (a rede das redes), a partir da década de 1990.

A palavra rede é outro termo que, assim como audiovisual, possui várias conotações. Definir atualmente o termo rede é algo complexo, já que se tornou polissêmico e ambíguo, o que pode levar a uma imprecisão do seu significado. Logo, estabelecer com precisão uma data de quando este termo foi criado é tão difícil quanto lhe atribuir um único sentido. A origem desta palavra vem do latim retis, que significa um conjunto de fios entrelaçados com aberturas regulares fixadas por malhas e nós formando um tecido aberto. A partir desta definição, a palavra rede passou a ser utilizada com diversas conotações e em diferentes áreas.

No sistema de radiodifusão, como o da televisão, a rede de transmissão é formada por um grupo de emissoras associadas ou afiliadas que transmitem toda ou grande parte da programação produzida por uma emissora geradora de conteúdos, também denominada de cabeça de rede. Em conformidade com a política adotada pelas redes de radiodifusão, as grandes emissoras são as produtoras e difusoras de conteúdos criados de acordo com sua percepção de sociedade, política, economia, educação e cultura. Dentro desta concepção de produção, as emissoras afiliadas acabam tendo pouco espaço na grade de programas para apresentar suas produções locais que retratem a identidade cultural da sua região. A maioria dos programas produzidos pelas emissoras afiliadas são telejornais locais. Isso demonstra que, na radiodifusão, as redes são verticalizadas de tal modo que os conteúdos produzidos por um centro gerador são retransmitidos para diversos pontos periféricos.

Esta é a lógica da chamada mídia de massa que opera no sentido "um-todos" e que considera o sujeito apenas como um espectador que assiste ao que lhe é transmitido. O sistema de radiodifusão realiza a distribuição, transmissão de conteúdos seguindo o 


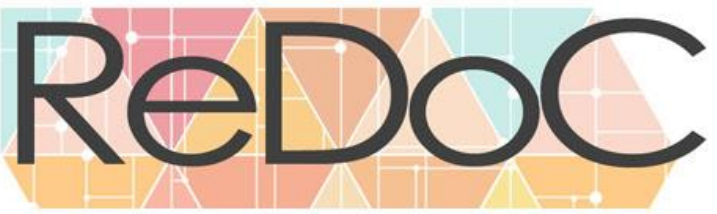

Revista Docência e Cibercultura

modelo clássico da informação emissor-menssagem-receptor. Esse modelo, não possibilita a intervenção de outros atores nos conteúdos produzidos. Ao espectador cabe apenas contemplar seus produtos sem a possibilidade de alterá-los.

As tecnologias digitais, que surgiram no final do século $\mathrm{XX}$, rompem com este paradigma linear da informação ao introduzir um novo elemento na comunicação a interatividade que oportuniza a coautoria e a intervenção na mensagem, nos conteúdos. Embora somente com as tecnologias digitais a interatividade tenha se tornado possível é importante ressaltar que a comunicação bidirecional foi um advento da radiocomunicação. O dramaturgo alemão Bertold Brecht (1898-1956) acreditava que se em cada residência tivesse um aparelho de rádio capaz de enviar e receber mensagens estariam assim oferecidas as condições para se instaurar uma "esfera pública cidadã", sustentada pela infraestrutura técnica, como viria a propor, anos depois, Habermas (1997) ao falar no mundo da vida como o espaço público onde acontece a ação comunicativa que seria a interação entre os sujeitos.

Com o desenvolvimento da internet surge a cibercultura definida por Lemos (2003, p. 12) como "a forma sócio-cultural que emerge da relação simbólica entre a sociedade, a cultura e as novas tecnologias de base micro-eletrônica que surgiram com a convergência das telecomunicações com a informática na década de 70”. Para Lemos (2009) a cibercultura está baseada em três princípios básicos: a liberação do polo da emissão que torna cada pessoa potencialmente produtora de conteúdos, informações em diferentes formatos vídeos, blogs, fotos, músicas etc.; a conexão em rede generalizada e aberta significa que toda a produção de informação é emitida, distribuída em rede com outros pares, outros grupo de forma planetária; a reconfiguração que modifica, mas não elimina as outras mídias. Com a reconfiguração a TV na internet passa a ser outra TV diferente da mídia de massa isso porque com a liberação do polo da emissão e a conexão em rede há uma necessidade de mudar, de transformar, de reconfigurar a cultura massiva.

A cibercultura é a cultura contemporânea que tem crescido amplamente com as tecnologias digitais móveis que possibilitam aos cidadãos comuns tornarem-se, com o usos de seus telefones celulares, sujeitos interagentes (PRIMO, 2007), a(u)tores 


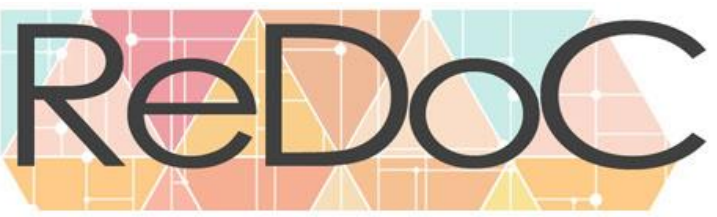

Revista Docência e Cibercultura

(LUCENA e PRETTO, 2009) de conteúdos e não mais espectadores que consumiam cultura de massa. Com as tecnologias móveis podemos estar em dupla mobilidade física e informacional ocupado espaços híbridos, intersticiais (SANTAELLA, 2007), ou seja, produzindo em movimento, uma das características dos sujeitos contemporâneos imersos na cibercultura.

Outra característica da cibercultura é a possibilidade de interatividade. Isso significa que não basta apenas produzir e publicar é preciso interagir. Vários autores apresentam diferentes conceitos de interatividade como Lévy (2000), Lemos (2001), Machado (1997), Couchot (1997) e Silva (2000). Dentre estes autores destacamos o conceito de Silva (2000) pelo fato deste autor não entender a interatividade apenas como um fenômeno das tecnologias digitais. De acordo com Silva (2000) a interatividade é uma forma de comunicação que pode ou não acontecer por meio das TIC. Para ele interatividade é uma

disponibilização consciente de um mais comunicacional de modo expressivamente complexo, ao mesmo tempo atentando para as interações existentes e promovendo mais e melhores interações - seja entre usuários e tecnologias digitais ou analógicas, seja nas relações "presenciais" ou "virtuais" entre seres humanos (SILVA, 2000, p. 20).

Para obter a interatividade, de acordo com Silva (2000), é preciso perceber se um determinado objeto, obra de arte ou mesmo equipamento digital, possui os fundamentos da interatividade, que ele classifica em três binômios: participaçãointervenção, bidirecionalidade-hibridação e potencialidade-permutabilidade. Silva chama a atenção de que estes fundamentos estão interligados.

No Brasil em 2002 um ex-diretor de uma emissora de televisão criou a primeira TV da internet brasileira a allTV com programação ao vivo durante 24 horas. Surgia ai outro jeito de fazer televisão com o perfil das quatro mídias: jornal, rádio, tevê e internet. $\mathrm{O}$ grande diferencial desta emissora da internet foi possibilitar aos internautas que acompanhavam a TV interagirem entre si e com os apresentadores nas salas de bate papo disponibilizadas no site da TV. Desta forma, o internauta tornava-se coautor dos programas, pois interagiam com perguntas e sugestões sobre o assunto que estivesse sendo debatido. 


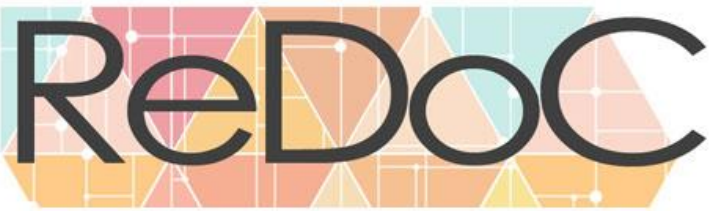

Revista Docência e Cibercultura

A partir desta experiência da allTV outros canais foram surgindo na internet discutindo temas variados. Algumas emissoras de TV também passaram a disponibilizar nos seus sites vídeos dos seus programas, porém este formato apenas apresentava o mesmo conteúdo distribuído no canal aberto da emissora, ou seja, sem nenhuma interatividade. A grande mudança do audiovisual na internet surgiu em 2005 quando foi criada a plataforma de compartilhamento de vídeo YouTube.

O grande sucesso do YouTube é sem dúvida a produção e compartilhamento de vídeos que qualquer pessoal pode fazer sobre qualquer assunto que deseje abordar. Isso fez com que o YouTube se tornasse o maior agregador de Webvídeos, com os mais variados assuntos sendo o terceiro site mais acessado atualmente no mundo antecedido apenas pelos sites Google e Facebook.

A popularização do YouTube cresceu bastante a partir da disseminação das tecnologias digitais móveis conectadas a internet. A comunicação destas tecnologias ocorre por meio de aplicativos conhecido também pela abreviatura App do termo em inglês applications. Os Apps são programas desenvolvidos para serem instalados em telefones celulares e demais dispositivos móveis disponibilizados gratuitamente ou não nas lojas online. Alguns Apps são software sociais, programas que simulam redes sociais e que possibilitam a criação de comunidades virtuais ou grupos com objetivos comuns que trabalham de forma colaborativa.

Atualmente existem Apps para várias funções, tais como: previsão do tempo, jogos, mapas, GPS, emissão de bilhetes de viagem, compra de ingressos, cuidados com a saúde, habilidades esportivas, moda, aplicações financeiras, produção de vídeos, comunicação e educação.

Para a produção e compartilhamento de vídeo um dos aplicativos existente é o Tellagami<https://tellagami.com/> . Este app, utilizado somente em dispositivos móveis, possibilita a criação e compartilhamento de pequenos vídeos denominados de Gamis. De acordo com Marques (2015) o Tellagami pode ser utilizado no contexto educacional das seguintes formas: na criação de histórias (digital storytelling), na explicação/demonstração de conceitos, na resolução de problemas de matemática, na criação de pequenos relatórios, no resumo ou apresentação de um livro (book trailer), no 


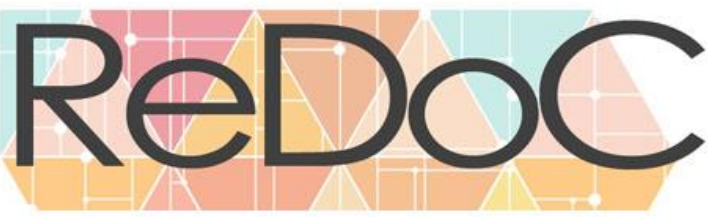

Revista Docência e Cibercultura

ensino e aprendizagem de línguas estrangeiras, na promoção da leitura e na criação de postais animados.

No que se refere a produção audiovisual temos no Brasil o app da TV Escola, disponível para sistema iOS e Android, que oferece uma programação diversificada. A TV Escola é uma emissora criada pelo Ministério da Educação desde 1999 com o objetivo inicial de promover a formação dos professores da educação básica, bem como disponibilizar conteúdos educacionais, por meio de programas, para diferentes disciplinas e níveis educacionais. O app da TV Escola possibilita assistir aos programas bem como fazer download e editá-los. Para acessar todos os conteúdos da plataforma TV Escola é preciso se cadastrar no site da TV.

Figura 3 - Aplicativo da TV Escola para tecnologias móveis

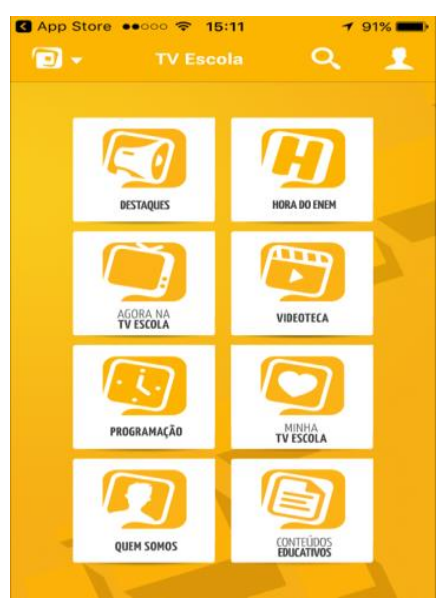

Fonte: http://www.tvescola.mec.gov.br

Além da TV Escola muitas outras televisões estão presentes na internet e com aplicativos para dispositivos móveis. O Canal Futura da Fundação Roberto Marinho é outro exemplo de TV na Web e que possui app. As televisões universitárias também tem se reconfigurado e disponibilizados seus conteúdos por diferentes interfaces e mídias. Entretanto, todas estas televisões, apesar de estarem utilizando uma nova plataforma na internet que potencializa interatividade e novas formas de produzir conteúdos, ainda estão presas à forma de comunicação linear da cultura de massa. 


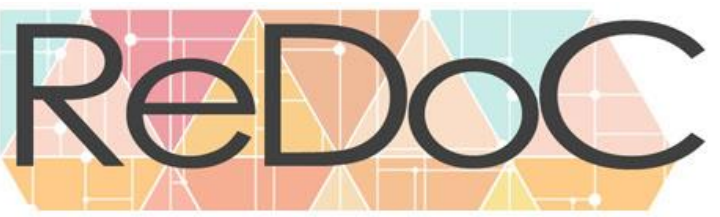

Revista Docência e Cibercultura

Nosso maior desafio, principalmente na educação, é pensar como utilizar as potencialidades da cibercultura para criar conteúdos coletivos, interativos, hipertextuais e não lineares em rede.

\section{CONCLUSÃO}

A internet possibilitou grandes mudanças na sociedade, pois trata-se de uma mídia que converge outras mídias. Porém, apesar da internet possibilitar esta convergência as outras mídias continuam existindo. Ainda lemos jornal, ouvimos rádio e assistimos cinema e televisão, contudo a presença da internet já alterou a forma como utilizamos estas tecnologias. Unir as potencialidades da televisão e da internet era inicialmente a das propostas para TV digital que devido às escolhas políticas e econômicas não se concretizou.

Apesar de toda a rede de pesquisa formada para o desenvolvimento de um padrão de TV digital brasileiro o governo do Brasil optou pela implantação do modelo de TV digital japonês com algumas adequações que possibilitaram a utilização da tecnologia desenvolvida pelos pesquisadores brasileiros. A TV digital é uma nova mídia que a depender as escolhas políticas e tecnológicas poderiam trazer grandes transformações socioculturais, porém apesar de todas as potencialidades desta nova mídia continuaremos a ter o mesmo modelo de produção e disponibização de conteúdos da televisão analógica, pois a TV digital aqui implantada apenas apresenta melhoria na qualidade da imagem e do som.

Vivemos uma nova era de comunicação generalizada que ocorre principalmente por meio das tecnologias digitais móveis que torna cada cidadão a(u)tor de conteúdos compartilhados em rede. É a era das mídias pós-massivas que operam numa outra lógica diferente das mídias de massa. As mídias pós-massivas potencializam o compartilhamento de saberes, a produção coletiva em mobilidade e a comunicação ubíqua. Neste sentido, a TV na internet ou WebTV necessita pensar em outros formatos de produção de conteúdos que tenham como pressupostos a interatividade, a hipertextualidade, a possibilidade de produção colaborativa e a publicação em rede. 


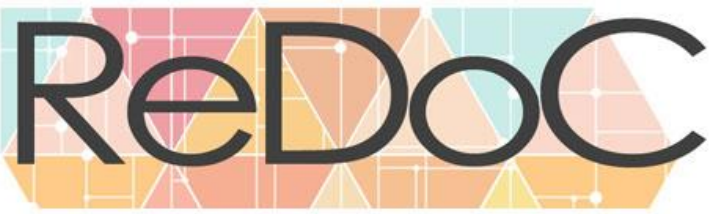

Revista Docência e Cibercultura

No campo educacional é de grande importância termos uma WebTV que possibilite os pressupostos acima citados para que cada escola de cada região ou estado brasileiro possa produzir e compartilhar conteúdos que tragam elementos da sua cultura, da sua realidade. Ter uma televisão que apenas disponibilize aos professores e alunos conteúdos prontos sem a possibilidade de interatividade é ter "mais do mesmo", pois esta foi a forma como a televisão analógica sempre operou com seus conteúdos. A WebTV, por ser uma mídia que converge outras mídias, outras linguagens e formatos, pode possibilitar novas formas de produzir e compartilhar o conhecimento.

\section{REFERÊNCIAS}

CAPARELLI, Sérgio. Comunicação de massas em massa. São Paulo: Summus, 1986.

COUCHOT, Edmund. A arte pode ainda ser um relógio que adianta? $\mathrm{O}$ autor, a obra e o espectador na hora do tempo real. In: DOMINGUES, Diana (Org.). A arte no século XXI: A humanização das tecnologias. São Paulo: Editora da UNESP, 1997.

HABERMA. Jürgen. Atores da sociedade civil, opinião pública e poder comunicativo. In: $O$ direito e a democracia: entre a facticidade e a validade. Vol. II. Rio de Janeiro, Tempo Brasileiro, 1997.

JAMBEIRO, Othon. A TV no Brasil do século XX. Salvador: Edufba, 2002.

LEMOS, André. Anjos Interativos e retribalização do mundo. Sobre interatividade e interfaces digitais. http://www.facom.ufba.br/pesq/cyber/lemos/interac.html - Capturado em $02 / 12 / 2001$

LEMOS, André. Cibercultura. Alguns pontos para compreender a nossa época. In: LEMOS, A.; CUNHA, P. Olhares sobre a cibercultura. Porto Alegre: Sulinas, 2003.

LEMOS, André. Cibercultura como Território Recombinante. In: Cazeloto, E., Trivinho, E.. (Org.). A cibercultura e seu espelho: campo de conhecimento emergente e nova vivência humana na era da imersão interativa. São Paulo: Itaú Cultural/Abciber, 2009.

LÈVY, Pierre. Cibercultura. Rio de Janeiro: Editora 34, 2000.

LUCENA, Simone; PRETTO, Nelson De Luca. . As novas educações e os potenciais da TV e das redes digitais. In: $32^{a}$ Reunião Anual da ANPED, 2009, Caxambu - MG. Sociedade, Cultura e educação: novas regulações. Rio de Janeiro: Anped, 2009. v. 1. p. $1-16$.

LUCENA, Simone. Educação e TV digital: situação e perspectiva. Maceió: EDUFAL, 


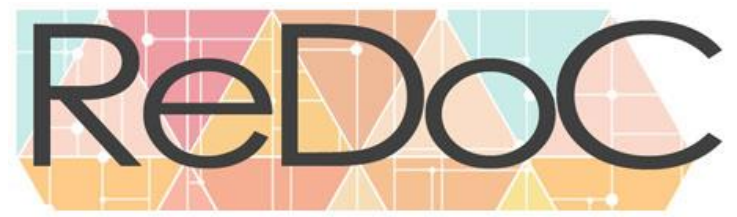

Revista Docência e Cibercultura

2012.

MACHADO, Arlindo. Pré-cinema \& pós-cinema. Campinas - SP: Papirus, 1997.

MARQUES, Célio Gpnçalves. Tellagami: criação e partilha de vídeos. In: CARVALHO, Ana Amélia A. (Org.). Apps para dispositivos móveis: manual para professores, formadores e bibliotecários. Ministério da Educação de Portugal. Direção Geral de Educação, 2015. Disponível em: <http://erte.dge.mec.pt/noticias/apps-paradispositivos-moveis-manual-para-professores-formadores-e-bibliotecarios> Acesso em 28 de jan. 2018.

MARTÍN-BARBERO, Jesús. Televisão pública, televisão cultural: entre a renovação e a invenção. In: Rincón, O. (Org.). Televisão pública: do consumidor ao cidadão. Quito, Equador: Editora: Friedrich Ebert Stiftung (FES), 2002.

MOTA, Maria Regina de Paula. TV Pública: educação e cidadania no ar. Dissertação (Mestrado em Educação). Universidade Federal de Minas Gerais, UFMG. Belo Horizonte, 1992.

MOTA, Regina. Os desafios da TV digital no Brasil. In: BARBOSA FILHO, André; CASTRO, Cosette; TOME, Takashi. (Orgs.). Mídias digitais: convergência tecnológica e inclusão social. São Paulo: Paulinas, 2005.

Pesquisa sobre o uso das tecnologias de informação e comunicação nos domicílios brasileiros [livro eletrônico]: TIC domicílios 2015. Núcleo de Informação e Coordenação do Ponto BR [editor]. São Paulo: Comitê Gestor da Internet no Brasil, 2016.

PRIMO, Alex. Interação mediada por computador: comunicação, cibercultura, cognição. Porto Alegre: Sulinas, 2007.

RABAÇA, Carlos Alberto \& BARBOSA, Gustavo Guimarães. Dicionário de Comunicação. Rio de Janeiro: Campus, 2001.

REY, Germán. O cenário móvel da televisão pública: Alguns elementos do contexto. In: Rincón, Omar (org.). Televisão pública: do consumidor ao cidadão. Quito, Equador: Editora: Friedrich Ebert Stiftung (FES), 2002.

SANTAELLA, Lucia. Linguagens líquidas na era da mobilidade. São Paulo: Paulus, 2007.

SILVA, Marco. Sala de aula interativa. Rio de Janeiro: Quartet, 2000. 